\title{
CONSIDERACIONES INTERDISCIPLINARES QUE DEBEN TRABAJAR HOY LOS JURISTAS Y LOS CRIMINOLOGOS
}

\author{
LUIS MARÍA DESIMONI \\ Reitor \\ Instituto Universitário da Polícia Federal, Argentina \\ luisdesimoni@yahoo.com.ar
}

\begin{abstract}
A tarefa da ordem jurídica é exatamente a de harmonizar as relações sociais intersubjetivas, a fim de ensejar a máxima realização dos valores humanos com o minimo de sacrifício e desgaste.
\end{abstract}

Grinover Ada Pellegrini.

En la primera edición de mi ensayo sobre DD.HH (1999), y pido excusas por lo autorefencial, y posteriormente en una tesis sobre: Los derechos humanos y la guerra contra el terror (2009) nos hemos referido a distintas aristas de naturaleza antropológica, sociológica, psicológica, médico legal y psicopatológica que impactan en la criminología y que no advertimos, sean tenidas en cuenta por los penalistas y criminólogos.

Insistimos en trabajos posteriores sobre el particular, ya que el derecho no es autosuficiente y el trabajo interdisciplinar será sin duda la impronta a futuro.

Para sustentar lo expresado es que me he permitido hacer una interpretación libre, de una cita del jurista Francisco Amaral, independientemente, que el citado se refiere a la rama del derecho privado. 
E por isso é conveniente, se não necessário, articular a ciência do direito, com as demais ciências sociais, de modo a compreender melhor o que realmente seja o direito. E, nesse processo interdisciplinar, ressalta a importância da história das instituições jurídicas, pois quem não tiver a percepção do sentido histórico do direito só pode ter dele uma visão estática.

Créemos que en definitiva es lo mismo en el mundo del derecho penal.

En cambio advertimos que algunos de los mas reconocidos juristas, hasta el presente, se parapetan fuertemente en un dogmatismo de raigambre alemana, y parecerían creer que esos principios sacros, impedirían las injusticias de este mundo en tanto, que otros centran su lucha en un problema politico, que no es otro que la permanente limitación del poder puntivo.

Será la nueva religión de nuestro tiempo ?

Ambas posturas a nuestro juicio abarcan el fenómeno que se pretende solucionar en forma insuficiente.

Reconocemos además que hay académicos nacionales e internacionales, que repiten posturas de otros académicos, interpretándolas, y aceptándolas o rechazándolas, y si bien en ocasiones sus diagnósticos sobre la cuestión criminal son acertados, a mi juicio adolecen de dos debilides:

a) insuficiencia del enfoque que no es interdisciplinar y

b) no aportan soluciones concretas, porqué la cuestión criminal, si se me permite llamarla así es muy compleja y cambiante y probablemente no tenga soluciones ni sencillas, ni menos aún definitivas. 
Abordar el tema de esta problemática es esencial para trabajar en serio por la vigencia de los derechos a la dignidad humana, ya que lo opuesto equivale a anclarse en discursos emocionales, que al común de las gentes no les solucionarán sus problemas cotidianos.

Y la Justicia, el Ministerio Público y las instituciones de Seguridad, no están para ello, es decir para hacer retórica, sina para aportar mejores gestiones operativas.

Las aristas a las que aludimos precedentemente son:

a) antropológico-filosóficas,

b) politico institucionales,

c) sistemicas penales $y$

d) sociológicas.

Ubi non est lex, nec societatem.

\section{a) Antropológico-Filosóficas}

El hombre exige ser reconocido en la complejidad de su ser, dado que a las dificultades que sobrevienen de su naturaleza individual, se opone la imposibilidad de proveer a sus necesidades en forma aislada. Esto se traduce en la formación de grupos humanos que se organizan bajo el fenómeno del Poder, y que luego devienen con el devenir de la historia en instituciones mas estructuradas, y que deben contar con sus necesarios liderazgos.

En ello el totem de piedra, el hechicero que luego dijo representarlo ante su tribu, y el más habil de los politicos actuales son sustancialmente lo mismo.

Lo expresado conduce al fenómeno de la poltica que es "la necesidad de un representación de intereses mayoritarios 
inconexos", y esto no es tan fácil porqué ello nos conduce a la consecuente dinámica del poder de quienes lo ejercen bajo la mascara de la autoridad.

Ese poder-autoridad se concreta mediante la creación de órganos y normas tendientes a lograr el siempre utópico "bien común", o, en palabras actuales, "proyectos sustentables para las generaciones presentes y futuras", que en ocasiones se intentan y en otras conducen a estrepitosos fracasos por problemas coyunturales o perfiles de personalidad de los dirigentes.

Me eximo de hacer nombres, ya bastantes se estará imaginando el lector al leer este trabajo, pero lo cierto es que algunos, por ineptitud o mala fé conducen a las hambrunas, las crisis y las guerras y otros intentan desarrollar un progreso sostenido del país que deben conducir.

Para colmo de males:

A cultura dos tempos modernos e uma ideologia, sobre a qual é baseada em três princípios básicos: a) individualismo, b) relativismo y c) o instrumentalismo. Dessa forma as obrigações que temos com as demais pessoas são secundarias e as pessoas se transformam em simples meios para chegar a um fim. (BARBOZA SILVA)

Por otra parte las instituciones no se reducen hoy al ámbito territorial de los Estados, sino que estos se interrelacionan, no sin desigualdades, y son impulsados por el fenómeno de la globalización a actuar en conjunto con organizaciones legales o ilegales, regionales y/o internacionales, sometidas a renovadas y permanentes transformaciones.

Aqui se debe enfrentar la permanente lucha del narcotráfico y el terrorismo yi-hadista, lo cual puede hacerse con eficien- 
cia y racionalidad o como salvajes que luchan con salvajes, y "dirty business" publicos o privados en el medio aprovechándose de todo ese río revuelto.

\section{b) Politico institucionales}

Las agrupaciones humanas constituidas bajo la figura jurídica del Estado y sus representantes políticos padecen la crisis de los sistemas normativos que regulan su vida social, y ya sea para afirmar la seguridad jurídica que como instituciones específicas están llamado a proveer, puede ocurrir que sean incapaces de evitar el debilitamiento progresivo de ese poder por falta de gestión y profesionalismo y es ahí donde en pro de fortalecer un poder que progresivamente se les debilita acuden al poder punitivo en forma irracional y desmedida.

Pese a esas crisis recurrentes que no aciertan a trabajar desde multiples aristas, tratan sólo de extender la órbita del derecho punitivo para lograr el cumplimiento de sus normas, claudicando con ello del carácter residual que los principios de los tratados internacionales asignan al ordenamiento penal en el desenvolvimiento de la vida de los Estados.

Otros estados populistas se covierten en estados "malhechores" al mejor estilo que hubiera sido, si el Medellin de Pablo Escobar, con el referido en la Presidencia, sustentando un regimen narcodemócrata en Colombia.

Hubo hombres que ofrendaron su vida como el ministro Lara Bonilla, y el candidato a la Presidencia Galan, mas muchos otros como políticos, periodistas, juevces y procuradores, en una guerra de baja intensidad en Medellin, sumando una férrea politica terminaron con ese fenómeno criminal, liderado por un psicópata de extrema peligrosidad pero que a su audacia y descontrol sin límtes sumaba un estilo estraté- 
gico cuasimilitar, sin discurso ni ideología, y con una fuerte acumulación de dinero mal habido y un fuerte culto a su personalidad criminal sin limites, como única bandera.

Su destrucción no terminó con el problema del narcotráfico porqué ese es un tema, que en ocasiones resulta lamentablemente funcional a algunos estados "malechores" con politicos inescrupulosos, que actúan en conexión con grupos mafiosos, recomendamos leer en este sentido el trabajo de Nando dalla Chiesa.

Nando dalla Chiesa, L'impresa mafiosa- Tra capitalismo violento e controllo sociale.

\section{c) Aspecto sistemico penal}

El fracaso de un sistema penal represivo, no representa sino el fracaso general de un sistema económico, social y político. Por ende, consideramos que las penas más severas no son la solución para que las problematícas referidas se minimicen. Ni que hablar, de un derecho penal para enemigos que sería un dogmatismo más, tan inutil como los demas dogmatismos, que devienen discursos no útiles a la realidad de un país y su ciudadanía.

En cuanto al narcotrafico al que me he referido, antes del mismo modo que el terrorismo que en no pocas ocasiones resultan funcionales, tales como lo demuestran Escobar en su link con la ETA, provocando el narcoterrorismo para paralizar al estado y destruir a los carteles rivales, y el 9-11 como resultado de negociaciones desventajosas del grupo tejano que estaba en el poder, con los lideres tribales que controlaban el precio del barril de petróleo. 


\section{d) Aspecto sociológico}

La profundización de las inequidades reveladas por una marginalidad creciente y una agudización de la brecha cultural entre los distintos segmentos de la población de la región latinoamericana, hace temer el quiebre de los órdenes jurídicos y reclama el compromiso de la comunidad para reducirlas, dado que las malas decisiones tendrán catastróficas consecuencias de largo plazo.

En este caso creo que el resultado temible sería una atomización, anárquica en la cual el todo vale será la regla en la dimensión sociológica, en tanto que en la normológica tendremos bellos tratados de excelsos profesores que no tendrán ninguna aplicación, ni provocarán una dimesión dikelógica moderna y respetuosa de los derechos humanos.

Algo así como sucedión con las prédicas de los "intelectuales jacobinos" de mayo de 1810, en el Rio de la Plata -hoy: Buenos Aires- Argentina- que recitaban y exaltaban los principios de la revolución francesa, en tanto que en el resto del país reinaba la anarquía y los liderazgos caudillistas con sus abusos y deguellos, y quiera Dios que me equivoque.

\section{Conclusiones}

El Estado y sus instituciones deberían -a mi juicio- ser reconceptualizados, y puestos al día, y los liderazgos se deben basar en un profesionalismo sustentado en proyectos solidos, para dotarlos de eficacia técnica y operativa en el uso del poder con fines de alta conducción profesional y los mecanismos institucionales requieren influir positivamente sobre los administrados en pro del bien común.

La doctrina en materia de derechos humanos debe ser reorientada: nacidas sus normas primeras a la luz del prin- 
cipio del respeto a los seres humanos frente al poder de los Estados, deben contemplar un mínimo de ética en los mecanismos de la globalización. En el siglo que se inicia se tienen que arbitrar instrumentos de protección de sectores colectivos expuestos al hambre, la ignorancia o la indigencia, como resultado de la ineficiencia o el desinterés, de los poderes territoriales en las que viven y de sus erráticas políticas económicas.

En los países de nuestra región se debería tratar la cuestión penal mediante técnicas minimalistas y de justicia restaurativa, en tanto que para los casos mas graves o los perfiles criminales mas peligrosos, se deben dictar condenas - sin soslayar en lo mas minimo el debido proceso, y el derecho de defensa, por las que amén de aplicar severas penas de prisión a los condenados de delitos graves, se proceda además al decomiso de los bienes, en caso que los condenados lo sean por corrupción, narcotráfico y terrorismo.- Con esto este autor cree que se desmotivaría ese tipo de injustos, mediante la confiscación de los bienes mal habidos que es lo que motiva los injustos, porqué las penas per se, sólo son útiles para separar a los mas agresivos de la sociedad.

El Estado debería conjuntamente con ONG -de probada probidad y sin ánimo de lucro- emplear y administrar los recursos obtenidos, mediante una recuperación confiscatoria, utilizándolos para reparar los daños causados por el delito en beneficio de la sociedad toda, invirtiendo que en la construcción de escuelas, hospitales o viviendas, o ayudando a la reinserción laboral de los marginados de la sociedad.

De todo esto se ocupan los académicos de Brasil y Argentina desde hace años en los claustros, y con Conferencias y Seminarios y fruto de ello son la tesis, artículos y tesinas que plasmaran las nuevas corrientes e ideas que ayudaran 
a una mejora permanente y sustenyable de nuestros países hermanos.

Llevamos dentro nuestro dos potencias enemigas: la gracia que viene de Dios y la voluntad que proviene de nosotros. Cuando la potencia grosera nos domina, la muerte del alma nos devora. (Shakespeare)

Habida cuenta todo lo que hemos expresado y la complejidad que tiene la naturaleza humana es que pensamos que en esta problemática los Estados tendrán que diagramar nuevos esquemas juridicos mas complejos y apoyados en soluciones interdisciplinarias, para amén de proteger a las personas del historico abuso de poder, siempre, como lograr además -y no hablo de emergencias- de proteger a esos mismos ciudadanos de seres marginales, y/o del crimen organizado que corróe toda la estructura del sistema.

El marginal causa una baja o varias al sistema, en tanto que los criminales organizados hieren de muerte al sistema todo, y provocan una destrucción de los derechos a la dignidad humana sistemicas, por vía de un estado anómino, malhechor o no, que teniendo el monopolio de la fuerza (vis armaque pro iure) dejan inermes a los ciudadanos y librados a su suerte.

A lo expresado llamo yo, contradicciones conceptuales ante la complejidad pragmatica y su prospectiva realista.

Desde la cátedra seguiremos trabajando para lograr nuevas propuestas y proyectos de tesis, que colaboren a intentar la mejoría de la "solución criminológica" en forma armónica y civilizada.

A fuer de sincero y a medida que me voy aproximando al cierre me asaltan dudas, acerca de la validez sacramental de la dogmática penal, y su concepción cuasi religiosa, como 
único seguro del derecho a la dignidad humana, que sin duda es una conquista que ha costado siglos y debe ser irreversible y ya lo he expresado en las conclusiones de mi libro anterior de esta misma editorial.

Pero paralelamente no puedo dejar de expresar que me surgen las preguntas recurrentes del para quien, o para quienes se sostiene esa dogmática.

La criminología presenta el problema de los psicópatas extremos -de clases marginadas y altas- y que para autores como Garrido conformarían una pandemia psicopatológica. Y la pregunta es que hacer con ellos? Ya que no son inimputables, y los mas extremos no son reinsertables en la sociedad.

Paralelamente su poder de daño es enorme, por lo cual provocan victimas por doquier y son además de la mano de obra de la que se nutren las organizaciones criminales organizadas.

Ante esta situación los penalistas, que parecen desconocer el tema psicopatológico y los perfiles criminales, nos hablan de no estigmatizar a los individuos, y dejar de lado el concepto de la peligrosidad y la reincidencia. Francamente no se entiende ese dogmatismo, que descuento se produce desde la mayor buena fé, sin reconocer tampoco el tema antropologico de la agresión destructiva, y todo ello se traduce en instalar el "animal planet imperium" en el cual los menos agresivos serán victimas de los agresivos, y el Estado en defensa de los derechos de autodetreminación de los agresivos de expandir su derecho a la agresividad, provocan víctimas por doquier, que deben tolerarlo como mansamente tolera la gacela ser devorada por un predador.

Francamente confieso que hay algo en todo este esquema que no cierra y por ello es las conclusiones lo expongo, porque de no encontrar "esos niveles con compatibles con el 
ejercicio de los derechos fundamentales" no habrá derechos fundamentales, porqué el Estado para evitar caer en el riesgo de violar los derechos de los agresivos que cometen injustos graves, y fijese el lector que me he cuidado al definirlos para no estigmatizarlos, se debe tolerar que las "buenas gentes de las que hablaba Carrara" deban tolerar amen de sus problemas existenciales daños, la posibilidad de cruzarse con un predador que los lesione o elimine.

Por ello expreso que los DD HH deben ser reprogramados, entendiendo esto como logrando esquemas superadores que tiendan hacia la civilización y nos alejen de la barbarie.

Autor convidado.

DOI: $10.5935 / 1809-8487.20160051$ 